\title{
PEMIKIRAN DAN PEMAKNAAN (KAJIAN SEMIOTIK) \\ LIRIK LAGU-LAGU THE TERIGGAS OF SAMBAS KARYA MUL'AM HUSAIRI WALID
}

\section{Agus Syahrani dan Muhammad Saiful Haq Bin Hussin}

\begin{abstract}
This study was conducted on a prominent humanist from Sambas, Pontianak, West Kalimantan to demonstrate his skill and effort in maintaining the Sambas Malay culture, especially through his singing.

He is also an expert in playing the traditional Malay instruments, namely rumian, drums, violin, harp, and others. Arising from the awareness on the importance of art conservation, especially Sambas Malay culture in particular, and regional Malay culture in general, he has established a working team to train and engage the young children in playing the drums. Based on his own collection, as well as his expertise in the field of Malay arts, he was appointed as a guest writer at the Academy of Malay Studies, University of Malaya. Therefore, this study will be focusing on his involvement in the field of art of music, throughout the Province of Sambas, West Kalimantan, Indonesia to the moment he successfully sustained the production of a compact disc entitled 'The Terrigas of Sambas' (Ngayatte 'ge song' Mare') which load the songs as listed below:
\end{abstract}

ALO' GALING LASSOUNG LABBAN

$A L O N-A L O N$

TA'ALLAW BINA

TIKANNANG URRANG TUE

CA' UNCANG 
Agus Syahrani dan Muhammad Saiful Haq Bin Hussin

\author{
TANDA' SAMBAS \\ KAPAL BELON \\ CIK-CIK PERIOUK \\ BATU BALLAH
}

\title{
LATAR BELAKANG KESULTANAN SAMBAS
}

Sumber yang digunakan oleh kaum sejarawan untuk melacak riwayat Kesultanan Sambas di Kalimantan Barat adalah dua kitab sastra bercorak sejarah, yaitu Asal Raja-Raja Sambas dan Salasilah Kerajaan Sambas (Pabali H. Musa, 2003:50). Kesultanan Sambas sebenarnya merupakan kelanjutan dari Kerajaan Hindu Ratu Sepudak atau Kerajaan Sambas Tua. Ekspedisi Pamalayu Majapahit pada abad ke-14 M sangat berpengaruh terhadap berdirinya Kerajaan Sambas Tua yang diawali oleh pemerintahan yang dipimpin Raden Janur dengan pusat pemerintahan di daerah bernama Paloh (Ratih, tt:1962). Seiring berkembangnya Islam di nusantara, pada tahun 1570 M, pengaruh Majapahit atas Kerajaan Sambas Tua mulai melemah. Pengaruh Islam yang masuk ke Kerajaan Sambas Tua sebenarnya datang dari Kesultanan Brunei Darussalam yang dipimpin Sultan Abdul Majid Hasan 1402 - 1408 M). Keturunan beliaulah yang bernama Pangeran Raja Tengah anak daripada Sultan Muhammad Hasan yang menurunkan para penguasa Kesultanan Sambas Islam (Fahmi [ed.], 2003:3). Putra sulung Pangeran Raja Tengah, yakni Raden Sulaiman yang dinobatkan sebagai Sultan Sambas dengan gelaran Sultan Muhammad Syafiuddin I di Muara Ulakan, dan membangun Istana Alwazikhoebillah. Kesultanan Sambas sangat kaya akan hasil hutan dan emas yang dapat menyejahterakan rakyat. Kejatuhan Kesultanan Sambas bermula daripada 1 Oktober 1696 M, wakil Belanda, Samuel Bloemaert, mengadakan perjanjian dagang dengan Kesultanan Sambas yang lebih banyak menguntungkan pihak Belanda. Belanda dengan mudah membawa hasil hutan dan emas dari Sambas menggunakan kapal-kapal besar untuk dibawa ke Batavia sebagai pusat pemerintahan jajahan Belanda. Hal ini membuat rakyat menjadi miskin walaupun memiliki hasil hutan dan emas yang melimpah. Rakyat marah dan melakukan perlawanan kepada pihak kolonial yang dipimpin oleh Pangeran Anom dengan gelar Sultan Muhammad Ali Syafiudin I yang memerintah (1815-1828). 


\section{BIODATA MULAM HUSAIRI WALID}

Mulam Husairi Walid adalah anak muda yang dilahirkan di Paloh Sambas pada 1 Januari 1972. Anak muda ini dibesarkan dengan didikan keras dari sang ayah, Haji Walid bin Abdul Jali. Didikan keras ini memaknai kegemarannya akan musik Melayu dan Islam yang tidak lazim disukai oleh anak muda pada masa itu. Kewajiban belajar mengaji, belajar bersalawat, belajar memainkan alat musik gambus, alat musik tar, menjadi aktivitas sehari-harinya di masa kecil. Didikan sang ayah inilah yang menjadikan Mulam menyenangi musik-musik tradisional, mengumpulkan barang antik, dan menyelidik secara otodidak. Fokus pada musik dan barang antik menjadikan Mulam benar-benar memahami bidang yang disebutnya "perjuangan Melayu" ini. Hal ini membuat dia menjadi kurator Museum Negeri Kalimantan Barat.

Beliau aktif dalam aktivitas-aktivitas kemasyarakatan Melayu, misalnya menjadi Ketua Forum Komunikasi Pemuda Melayu Kalimantan Barat, aktif dalam Majelis Adat Budaya Melayu Kalimantan Barat, dewan pakar dalam Dewan Kesenian dan Kebudayaan Sambas, dan ahli dalam Lembaga Adat Melayu Serantau. Anak muda yang berumur 40 tahun ini juga mendirikan Yayasan Pesisir Kalimantan Barat. Yayasan ini pula yang menjadi tempat baginya untuk beraktivitas secara meluas di Sambas untuk mengangkat budaya Melayu. Beliau memainkan peranan dalam membina rumah budaya zikir, rumah budaya tari Melayu, dan rumah budaya musik Melayu tradisional. Beliau juga mencoba membangkitkan seni ukir Melayu dengan melatih dan mempublikasikan hasil ukiran Melayu Sambas dalam pelbagai pertunjukan. Beliau juga membuat alat-alat musik tradisional seperti tar, gambus, rebana, dan beduk yang dibagikan kepada kumpulankumpulan rumah budaya dan sekolah-sekolah. Beliau juga mendesain sendiri corak-corak baru tenun Sambas seperti corak daun kesum, corak daun galli, dan corak bulan bintang. Beliau juga sering mewakili Sambas dalam mengikuti kegiatan pameran, budaya, tradisi, artifak Melayu di tingkat bangsa maupun antara bangsa.

Kecintaannya akan musik Melayu yang sewaktu kecil telah diajarkan oleh ayahanda menjadikannya menumbuhkan kelompok anak-anak kecil yang bertujuan untuk melatih mereka sejak dari rebung lagi. Kecintaannya terhadap musik tradisional Melayu membuatnya mencipta sebuah album musik Melayu tradisional yang berjudul the Teriggas of Sambas (Ngayatte' lagu ge' mare'). Album musik ini merupakan kumpulan lagu-lagu tradisional 
lama Sambas yang diubah dengan pendekatan musik sekarang. Album ini terbukti diterima oleh semua lapisan masyarakat Sambas. Mulam berperan sebagai pengarah vokal, komposer, dan sekaligus pemain musik itu sendiri.

\section{THE TERIGGAS OF SAMBAS}

The Teriggas of Sambas ('Ngayattte' Lagu ge' Marek') yang bermaksud menghayati lagu-lagu lama. Menelusuri jejak peradaban Melayu Sambas melalui lagu didapati telah memberikan sumbangan yang besar sebagai tonggak dalam penyelidikan bidang-bidang arkeologi, naskah, budaya, teknologi dan pengkajian sejarah yang lain. Perjalanan evolusi sebuah lagu sampai kini menunjukkan bahwa identitas Melayu tercipta dan terbentuk daripada kepelbagaian suku bangsa, bahasa, dan budaya yang disatukan oleh Islam (Melayu adalah Islam dan Islam adalah Melayu) dalam satu komunitas besar yang menghiasi Nusantara khususnya di Kabupaten Sambas dan dunia umumnya.

Menyorot koleksi lagu-lagu lama dalam cakera padat 'Ngayatte' Lagu

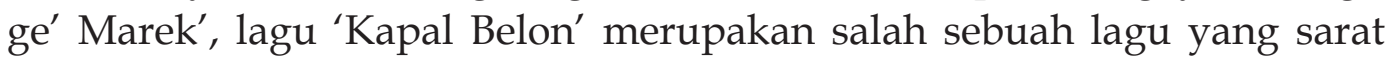
dengan pemikiran Melayu pada zaman kegemilangannya. Bukti ini dapat dilihat melalui surat Sultan Kassim Al Qadri kepada Sir Stamford Raffles pada 14 Feb 1811, 12 Maret 1811 dan 22 Maret 1811 (lihat lampiran A, B, C).

\section{LAGU 'KAPAL BELON'}

Ya kapal ya Kapal Belon, kapal belon nujju ke Saboung.

Ya kapal ya Kapal Belon, kapal belon nujju ke Saboung.

Ape lah muattan jeluttoung gattah jeluttoung.

Ape lah muattan jeluttoung gattah jeluttoung.

Ya baju ya baju ya baju merah, baju merah silendang gadoung.

Sodah na' sukke mbirrah, tahhan nafsu di gantoung.

Sodah na' sukke mbirrah, tahhan nafsu di gantoung.

Sari Borneo namenye kapal, masouk Sambas selalu sakkal.

Nakhodenye inda' berakal.

Taukan batu maseh di baddal.

Taukan, taukanlah batu maseh di baddal.

Sultan Sambas sulohlah nagri.

Ge'mare': Jamman udah be passan.

Sultan Sambas sulohlah nagri.

Ge'mare': Jamman udah be passan. 
Jagelah anak binni, mun da' djage dimakan jaman.

Jagelah anak binni kalla' dimakan jaman.

\section{SINOPSIS LAGU 'KAPAL BELON’}

Kapal Belon/Belee (luar biasa) artinya adalah kapal yang teramat besar dari Sambas ke luar negara mengangkut berbagai barang ekspor Kesultanan Sambas. Hal ini karena pada zaman kegemilangan Kesultanan Sambas merupakan pusat perdagangan di Nusantara (Kontrak dagang tertua di Indonesia adalah di antara kesultanan Sambas dengan VOC Belanda - 1603: Arsip Nasional). Hal ini mungkin saja yang dimuatkan dalam kapal pada masa itu bukan hanya karet (Gattah Jeluttong), tetapi juga emas, karena Kesultanan Sambas pada umumnya menyimpan banyak sekali sejarah mengenai emas dan tambangnya.

\section{ANALISIS PEMIKIRAN DALAM LAGU 'KAPAL BELON'}

Lagu 'Kapal Belon' mengisahkan tentang peristiwa kapal yang teramat besar dari Sambas keluar negara mengangkut berbagai barang ekspor Kesultanan Sambas. Cerita yang ingin dikisahkan adalah mengenai sistem pengangkutan air yang sangat penting pada masa dahulu untuk tujuan perdagangan antara bangsa. Hasil penyelidikan membuktikan bahwa kisah kapal besar yang digunakan itu terbukti kebenarannya. Sebagaimana dalam surat Sultan Kasim Alqadri kepada Sir Stamford Raffles pada 14 Februari 1811, 12 Maret 1811, dan 22 Maret 1811. Sultan Syarif Kasim Alqadrie adalah sultan yang memerintah kesultanan Pontianak dari tahun 1808 1819. Baginda merupakan sultan kedua setelah ayahandanya Sultan Syarif Abdurrahman Alqadrie mendirikan kesultanan Pontianak pada 23 Oktober 1771 Masehi bertepatan 12 hari bulan Rajab tahun 1185 serta memerintah dari tahun 1778 - 1808.

Baginda telah memaklumkan kepada Raffles melalui suratnya pada 14 Februari 1811 bahwa baginda meminta bantuan kepada beliau karena Pontianak diancam oleh lanun di bawah pimpinan Sultan dan Pangeran Anom dari Sambas. Sultan Sambas telah bekerjasama dengan lanun untuk menyerang para pedagang yang berdagang dan berniaga di Pontianak, Mempawah, dan Banjar. Baginda telah memberi peringatan kepada Raffles sekiranya beliau tidak mengambil tindakan, pihak Inggris akan terkena dampak dari kegiatan mereka itu. Menurut baginda:

... Jika boleh dengan sebolehnya sahabat kita tolong seboleh- 
bolehnya kerja habis itu perompak2 dan Ilanun segala yang kerja jahat2 sama orang dagang itu, karena kepada ketika ini semuanya ada berkumpul dalam negeri Sambas dan berkumpul di laut kuala negeri Mempawah dan Pontianak demikianlah adanya. Dan kepada kita punya fikiran jika Kompeni Inggris tiada mahu tolong kerja habis itu perompak2 itu pastilah di belakang ia kerja kembali kerja rosak sama orang putih karena yang kita tahu ini telah tiga kali sudah Pangeran Anom beserta Sultan Sambas ini kerja jahat sama Inggris ...

... dan kepada kita punya fikiran, jika kompeni Inggris tiada mahu tolong kerja habis itu perampok2 itu, pastilah di belakang ia kerja kembali kerja rosak sama orang putih, karena yang kita tahu ini telah tiga kali sudah Pangeran Anom beserta Sultan Sambas ini kerja jahat sama Inggris; pertama2, bunuh Kapitan Rasdil; keduanya, bunuh mualim kapal commerce itu; ketiganya, ambil harta Kapitan Ross bersama2 Abang Abdul Rasyid itu. ...

Lebih kurang sebulan kemudian, baginda mengutus lagi warkah yang bertarikh 12 Maret 1811 dan dalam warkah ini Sultan Syarif Kasim Alqadrie telah menyatakan bahwa Pangeran Anom dari negeri Sambas dan Abdul Rasyid Mentok telah merampas kapal Mister Hare Melaka dan juga merampas sebuah wangkang dari Cina yang datang untuk berniaga di Pontianak dan Mempawah. Mereka telah merusakkan perdagangan dan mengganggu para pedagang yang keluar dan masuk berdagang. Baginda telah meminta bantuan Raffles agar sebuah kapal perang diantar dengan segera ke Pontianak untuk menangkap pencuri-pencuri tersebut karena mereka berada di laut Kuala Pontianak. Menurut baginda:

... Maka inilah jika boleh dengan bolehnya kita minta tolong kepada sahabat kita menolong menyuruhkan sebuah kapal perang ke Puntianak menangkap si pencuri itu, dan kita pun boleh pergi bersama2 kapal perang itu menangkap si pencuri itu. Jika tiada sahabat kita segera menyuruhkan lekas2 kapal perang datang pasti ada terlalu banyak susah segala orang2 dagang yang masuk keluar berniaga di negeri Pontianak itu adanya ...

... dipermaklumkan oleh Sultan Syarif Kasim Alqadrie kepada sahabat kita Tuan Raffles maka adalah kita memberi khabar kepada sahabat kita akan hal Pangeran Anom Sambas beserta Abdul Rasyid Mento' itu datang ke Kuala Pontianak merampok2 bersama2 ilanun mengambil sebuah wangkang Cina, ...

... maka telah sangatlah harap kita dengan amat besar pengharapan kepada sahabat kita Tuan Raffles Esquire akan menyuruhkan sebuah kapal perang datang ke Pontianak dengan segeranya, karena Pangeran Anom beserta Abdul Rasyid itu ada sedia di laut Kuala Pontianak merompak2 dengan dua buah kapal kecil jua adanya. ... 
Warkah ketiga baginda pada 22 Maret 1811, baginda tidak jemu-jemu memaklumkan kepada Raffles bahwa Pangeran Anom Sambas serta Abdul Rasyid Mentok telah membunuh Kapitan Ross di laut Mentok. Baginda memaklumkan sekali lagi masalah yang dihadapi akibat kegiatan lanun di Pontianak. Dalam dua bulan sahaja tiga pucuk warkah telah dikirimkan oleh baginda kepada Raffles untuk memaklumkan bahwa Pontianak berada dalam keadaan tidak aman akibat daripada kegiatan lanun dan perampokan yang dilakukan oleh Pangeran Anom dan Abdul Rasyid Mentok. Menurut baginda:

... jika tiada sahabat kita segera menyuruh lekas2 kapal perang datang, pasti ada terlalu banyak susah segala orang2 dagang yang masuk keluar berniaga di negeri Pontianak itu adanya. ...

... maka inilah jika boleh dengan bolehnya kita minta' tolong kepada sahabat kita menolong menyuruhkan sebuah kapal perang ke Pontianak menangkap si pencuri itu, dan kita pun boleh pergi bersama2 kapal perang itu menangkap si pencuri itu. Jika tiada sahabat kita segera menyuruhkan lekas2 kapal perang datang, pasti ada terlalu banyak susah segala orang2 dagang yang masuk keluar berniaga di negeri Pontianak itu adanya. Maka telah sangatlah harap kita dengan amat besar pengharapan kepada sahabat kita Tuan Thomas Raffles Esquire akan me\{n\}yuruhkan sebuah kapal perang datang ke Pontianak dengan segeranya, karena Pangeran Anom beserta Abdul Rasyid itu ada sedia di laut Kuala Pontianak merompak2 dengan dua buah kapal kecil jua adanya.

Perkara yang sama juga berlaku dalam warkah baginda pada 6 Februari 1814, yaitu tiga tahun kemudian. Warkah ini berkaitan dengan isi warkah pertama hingga ketiga terdahulu yaitu baginda memaklumkan bahwa negeri Pontianak, Mempawah, Matan, dan Sambas semuanya baikbaik saja dan tidak ada lagi lanun yang mengancam sewaktu warkah ini ditulis. Namun, baginda memaklumkan bahwa Pangeran Anom telah datang kembali ke Sambas dari hulu (Kawasan Dayak).

Pemikiran tersirat dari Mulam Husairi Walid dalam mengangkat lagu ini adalah untuk membina kembali kekuatan Melayu sebagaimana kehebatan Melayu dahulu. Kekuatan Melayu akan bersatu dalam horizon yang lebih luas, sekali gus meruntuhkan batas politik palsu yang sering melemahkan bangsa Melayu. 


\section{ANALISIS PEMAKNAAN DALAM LAGU ‘KAPAL BELON’}

Teori semiotika yang diacu untuk menganalisis lirik-lirik lagu Melayu Sambas dalam album The Teriggas of Sambas adalah teori yang dikembangkan oleh Riffaterre (1978). Riffaterre menganggap bahwa puisi adalah sebagai salah satu wujud aktivitas bahasa. Sebagai salah satu wujud aktivitas bahasa, puisi berbicara mengenai sesuatu hal dengan maksud yang lain. Artinya, puisi berbicara secara tidak langsung sehingga bahasa yang digunakan pun berbeda dari bahasa sehari-hari. Laras bahasa puisi tersebut disebabkan oleh penggubahan makna, penciptaan makna baru, dan perusakan makna kebahasaan sehari-hari. Oleh karena itu, untuk menganalisis lirik-lirik lagu Melayu Sambas dalam album The Teriggas of Sambas dapat menggunakan dua teknik yaitu: (1) pembacaan heuristik, dan (2) pembacaan hermeneutik.

\section{Pembacaan Heuristik}

Pembacaan heuristik merupakan pembacaan tingkat pertama untuk memahami makna secara linguistik (Riffaterre, 1978:5). Sedangkan menurut Santosa (2004:231) pembacaan heuristik adalah pembacaan yang didasarkan pada konvensi bahasa yang bersifat mimetik (tiruan alam) dan membangun serangkaian arti yang heterogen, berserak-serakan. Hal ini dapat terjadi karena hanya didasarkan pada pemahaman arti kebahasaan yang bersifat lugas atau berdasarkan arti denotatif dari suatu bahasa. Selain itu, Pradopo (2010:135) memberi definisi pambacaan heuristik yaitu pembacaan berdasarkan struktur bahasanya atau secara semiotik adalah berdasarkan konvensi sistem semiotik tingkat pertama. Oleh karena itu, pada tahap ini pembaca masih kurang puas dengan hasil yang dicapai sehingga harus dilakukan dengan pembacaan hermeneutik.

Pembacaan heuristik adalah pembacaan yang didasarkan pada konvensi bahasa yang bersifat mimetik (tiruan alam) dan membangun serangkaian arti yang heterogen, berserak-serakan. Hal ini dapat terjadi karena hanya didasarkan pada pemahaman arti kebahasaan yang bersifat lugas atau berdasarkan arti denotatif dari suatu bahasa. Pembacaan heuristik ini dilakukan dengan cara mengartikan setiap kata sesuai dengan makna leksikalnya atau sesuai dengan arti KBBI (Kamus Besar Bahasa Indonesia).

Ya kapal ya kapal belon, merupakan kalimat yang dibangun dari kata ya, kapal, ya, kapal, dan belon. Kata ya (itu) berarti kata penunjuk bagi benda (waktu, hal) yang jauh dari pembicara. Kata kapal berarti kendaraan pengangkut penumpang dan barang di laut (sungai dan sebagainya). 
Kata ya (itu) berarti kata penunjuk bagi benda (waktu, hal) yang jauh dari pembicara. Kata kapal berarti kendaraan pengangkut penumpang dan barang di laut (sungai dan sebagainya). Kata belon berarti belum lolos dari daerah penjagaan (pada permainan galah panjang).

Kapal belon nujju ke Saboung merupakan kalimat yang dibangun dari kata kapal, belon, nujju, ke, dan saboung. Kata kapal berarti kendaraan pengangkut penumpang dan barang di laut (sungai dan sebagainya). Kata belon berarti belum lolos dari daerah penjagaan (pada permainan galah panjang). Kata nujju (menuju) berarti pergi ke arah; mengarah (ke). Kata ke berarti kata depan yang menunjukkan tempat. Kata Saboung berarti nama kampung yang berada di kabupaten Sambas. Kalimat itu diulang kembali pada larik pertama dan kedua yang fungsinya untuk mempertegas makna kalimat di atas.

Ape lah muattan jeluttoung gattah jeluttoung merupakan kalimat yang dibangun dari kata ape, lah, muattan, jeluttoung, gattah, dan jeluttoung. Kata ape berarti kata tanya untuk menanyakan nama (jenis, sifat) sesuatu. Kata lah berarti bentuk terikat yang digunakan untuk menekankan makna kata yang di depannya. Kata muattan (muatan) berarti 1) barang yang diangkut dengan kendaraan; 2) isi (kapal dan sebagainya). Kata jeluttoung (karet) berarti tumbuhan besar yang tingginya mencapai $5 \mathrm{~m}$ dan kulit batangnya menghasilkan getah yang digunakan sebagai bahan membuat ban, bola, dan sebagainya. Kata gattah (getah) berarti zat cair pekat dari batang kayu, buah-buahan, dan sebagainya yang bersifat melekat; 2 . zat cair pekat dari pohon karet (perca). Kata jeluttoung (karet) berarti tumbuhan besar yang tingginya mencapai $5 \mathrm{~m}$ dan kulit batangnya menghasilkan getah yang digunakan sebagai bahan membuat ban, bola, dan sebagainya; pohon para. Kalimat lagu itu diulang kembali pada larik ketiga dan keempat yang fungsinya untuk mendapatkan efek keindahan dan untuk mempertegas makna kalimat di atas.

Ya baju ya baju merah, baju merah silendang gadoung merupakan kalimat yang dibangun dari kata ya, baju, ya, baju, merah, baju, merah, silendang, dan gadoung. Kata ya (yang) berarti kata untuk menyatakan bahwa kata atau kalimat yang berikut diutamakan atau dibedakan dari yang lain. Kata baju berarti pakaian penutup badan bagian atas (banyak ragam dan namanya). Kata ya (yang) berarti kata untuk menyatakan bahwa kata atau kalimat yang berikut diutamakan atau dibedakan dari yang lain. Kata baju berarti pakaian penutup badan bagian atas (banyak ragam dan namanya). Kata $\underline{\text { merah berarti warna dasar yang serupa dengan warna darah. Kata baju }}$ 
berarti pakaian penutup badan bagian atas (banyak ragam dan namanya). Kata merah berarti warna dasar yang serupa dengan warna darah. Kata silendang (selendang) berarti kain (sutra dan sebagainya) panjang penutup leher (bahu, kepala) atau untuk menari. Kata gadoung (gadung) berarti hijau muda.

Sodah na' sukke mbirrah, tahhan tahhan nafsu digantoung merupakan kalimat yang dibangun dari kata sodah, $n a^{\prime}$, sukke, mbirrah, tahhan, tahhan, nafsu, dan digantoung. Kata sodah (sudah) berarti telah jadi; telah sedia; selesai. Kata $n a^{\prime}$ (hendak) berarti mau; berhasrat. Kata sukke (suka) berarti 1) berkeadaan senang (girang) 2) girang hati; senang hati. Kata mbirrah (membirah) berarti kegatalan terhadap sesuatu (seperti kepada seseorang). Kata tahhan (tahan) berarti tetap keadaannya (kedudukannya dan sebagainya) meskipun mengalami berbagai hal; tidak lekas rusak (berubah, kalah, luntur, dan sebagainya). Kata tahhan (tahan) berarti tetap keadaannya (kedudukannya dan sebagainya) meskipun mengalami berbagai-bagai hal; tidak lekas rusak (berubah, kalah, luntur, dan sebagainya). Kata nafsu berarti keinginan (kecenderungan, dorongan) hati yang kuat. Kata gantung berarti sangkut; kait. Kata - di adalah bentuk terikat yang cara penulisan digabung. Kalimat itu diulang kembali pada larik kedua dan ketiga yang fungsinya untuk mempertegas makna kalimat kata di atas.

Sari borneo namenye kapal, masouk Sambas silalu sakal merupakan kalimat yang dibangun dari kata sari, borneo, nama, nye, kapal, masouk, dan Sambas. Kata sari berarti 1) isi utama (dari suatu benda); pati; 2) pakaian wanita tanpa jahitan, panjangnya 5-7 $\mathrm{m}$, terlilit rapi, ujung yang satu menutup tubuh, ujung yang lain disampirkan di pundak dan terjuntai di dada. Kata borneo oleh orang zaman sinkretik menyebutnya adalah baptis yang berarti penggunaan air untuk penyucian keagamaan, khususnya sebagai sakramen penerimaan seseorang ke dalam agama Kristen. Kata nama berarti kata untuk menyebut atau memanggil orang (tempat, barang, binatang, dan sebagainya). Kata -nya merupakan kependekan dari kata punya yang menunjukkan kepunyaan atau kepemilikan. Kata kapal berarti kendaraan pengangkut penumpang dan barang di laut (sungai dan sebagainya). Kata masouk (masuk) berarti datang (pergi) ke dalam (ruangan, kamar, lingkungan, dan sebagainya).Kata Sambas dalam kamus bahasa Indonesia adalah "Samba" berarti bersukaria. Kata silalu (selalu) berarti senantiasa atau selamanya. Kata sakal berarti pukulan; dan benturan.

Nakhodenye inda' berakal merupakan kalimat yang dibangun dari kata nakhode, -nye, inda', dan berakal. Kata nakhode (nakhoda) berarti 1) juragan 
(pemimpin) perahu (kapal); 2) perwira laut yang memegang komando tertinggi di atas kapal niaga; kapten kapal. Kata inda' (tidak) berarti partikel untuk menyatakan pengingkaran, penolakan, penyangkalan, dan sebagainya; tiada. Kata akal berarti daya pikir (untuk memahami sesuatu dan sebagainya); pikiran; ingatan. Kata ber- merupakan prefiks pembentuk verba yang artinya mempunyai.

Taukan batu maseh dibaddal merupakan kalimat yang dibangun dari kalimat tau, kan, batu, maseh, di, dan baddal. Kata tau berarti mengerti sesudah melihat (menyaksikan, mengalami, dan sebagainya). Kata -kan merupakan sufiks pembentuk verba yang bermakna menjadikan. Kata batu berarti benda keras dan padat yang berasal dari bumi atau planet lain, tetapi bukan logam. Kata maseh (masih) berarti sedang dalam keadaan belum selesai atau sedang berlangsung. Kata di merupakan bentuk prefiks pembentuk verba dan dikenai suatu tindakan. Kata baddal (langgar) berarti bertubrukan; bertumbukan; serang menyerang. Kalimat itu diulang kembali pada larik keempat bait ketiga dengan maksud untuk mempertegas makna kalimat tersebut.

Sulthan Sambas sullohlah nagri merupakan kalimat yang dibangun dari kalimat sulthan, Sambas, sulloh, -lah, dan nagri. Kata sulthan (sultan) berarti raja atau baginda. Kata Sambas dalam kamus bahasa Indonesia adalah"Samba" berarti bersukaria. Kata sulloh (suruh) berarti perintah (supaya melakukan sesuatu). Kata -lah merupakan bentuk terikat yang digunakan untuk menekankan makna kata yang di depannya. Kata nagri (negeri) berarti tanah tempat tinggal suatu bangsa.

Ge' mare' jamman uddah bepassan merupakan kalimat yang dibangun dari kata ge', marre', jamman, uddah, be, dan passan. Kata ge' (pada) berarti kata depan yang dipakai untuk menunjukkan posisi di atas atau di dalam hubungan dengan, searti dengandi (dipakai di depan kata benda, kata ganti orang, keterangan waktu) atau ke. Kata marre' (dahulu) berarti waktu yang telah lalu; masa lampau. Kata jamman (zaman) berarti jangka waktu yang panjang atau pendek yang menandai sesuatu; masa. Kata uddah (sudah) berarti telah jadi; telah sedia; selesai. Kata passan (pesan) berarti perintah, nasihat, permintaan, amanat yang disampaikan lewat orang lain. Kata bermerupakan prefiks pembentuk verba yang artinya mempunyai.

Jagelah anak binni, mun da' dijage dimakan jaman merupakan kalimat yang dibangun dari kata jage, -lah, anak, binni, mun, da', di, jage, di, makan, dan jaman. Kata jage (jaga) berarti bangun; tidak tidur. Kata -lah merupakan 
bentuk terikat yang digunakan untuk menekankan makna kata yang di depannya. Kata anak berarti keturunan yang kedua; manusia yang masih kecil. Kata binni (istri) berarti wanita (perempuan) yang telah menikah atau yang bersuami.

Kata mun (kalau) berarti kata penghubung untuk menandai syarat; seandainya. Kata $d a^{\prime}$ (tidak) berarti partikel untuk menyatakan pengingkaran, penolakan, penyangkalan, dan sebagainya; tiada. Kata di merupakan bentuk prefiks pembentuk verba dan dikenai suatu tindakan. Kata jage (jaga) berarti bangun; tidak tidur. Kata di merupakan bentuk prefiks pembentuk verba dan dikenai suatu tindakan. Kata makan berarti memasukkan makanan pokok ke dalam mulut serta mengunyah dan menelannya. Kata jaman (zaman) berarti jangka waktu yang panjang atau pendek yang menandai sesuatu; masa.

\section{Pembacaan Hermeneutik}

Secara etimologis hermeneutika berasal dari kata hermeneuein, bahasa Yunani, yang berarti menafsirkan atau menginterpretasikan. Secara mitologis hermeneutika dikaitkan dengan Hermes, nama Dewa Yunani yang menyampaikan pesan Illahi kepada manusia. Pada dasarnya medium pesan adalah bahasa, baik bahasa lisan maupun bahasa tulisan. Jadi, penafsiran disampaikan lewat bahasa, bukan bahasa itu sendiri. Karya sastra perlu ditafsirkan sebab di satu pihak karya sastra terdiri atas bahasa, di pihak lain, di dalam bahasa sangat banyak makna yang tersembunyi, atau dengan sengaja disembunyikan (Ratna, 2004:45).

Pembacaan hermeneutik adalah pembacaan yang bermuara pada ditemukannnya satuan makna puisi secara utuh dan terpadu (Santosa, 2004:234). Sementara itu, Pradopo (2010:137) mengartikan pembacaan hermeneutik sebagai pembacaan berdasarkan konvensi sistem semiotik tingkat kedua (makna konotasi). Pada tahap ini, pembaca harus meninjau kembali dan membandingkan hal-hal yang telah dibacanya pada tahap pembacaan heuristik. Dengan cara demikian, pembaca dapat memodifikasi pemahamannya dengan pemahaman yang terjadi dalam pembacaan hermeneutik.

Sehubungan dengan itu, puisi harus dipahami sebagai sebuah satuan yang bersifat struktural atau bangunan yang tersusun dari berbagai unsur kebahasaan. Oleh karena itu, pembacaan hermeniutik pun dilakukan secara struktural. Artinya, pembacaan itu bergerak secara bolak balik dari satu 
bagian ke keseluruhan dan kembali ke bagian yang lain dan seterusnya. Pembacaan ini dilakukan pada interpretasi hipogram potensial, hipogram aktual, matriks, dan model.

\section{Hipogram Potensial}

Hipogram potensial adalah segala bentuk implikasi dari makna kebahasaan, yaitu yang berupa makna konotatif yang sudah dianggap umum. Implikasi itu tidak dapat ditemukan dalam kamus, baik kamus ekabahasa maupun kamus dwibahasa, karena implikasi bukan berdasarkan pada arti denotatif kebahasaan. Implikasi itu sebenarnya telah ada pada pikiran penutur bahasa pada umumnya.

Dalam bait pertama Ya Kapal Ya Kapal Belon, Kapal Belon Nujju Ke Saboung mengimplikasikan adanya sebuah kapal yang bernama belon. Pada pembacaan heuristik kapal belon adalah kendaraan yang mengangkut penumpang atau barang dari suatu daerah. Setelah dilakukan pembacaan secara hermeneutik kapal belon ini mengandung makna konotatif merupakan kapal yang teramat besar atau kapal modern pada zaman dahulu yang mengangkut berbagai barangan ekspor Kesultanan Sambas keluar negara. Hal itu terjadi kerana pada zaman kegemilangan kerajaan kesultanan, Sambas merupakan sebuah pusat perdagangan di Nusantara (Kontrak dagang tertua di Indonesia adalah di antara Kesultanan Sambas dengan VOC Belanda - 1603: Arsip Nasional). Jadi, kapal belon ini mengungkapkan kondisi perekonomian Sambas yang sangat maju dan lancar dan orang-orang Sambas pada saat itu sangat kaya-kaya. Kata saboung menerangkan bahwa kapal belon ini berlayar menuju ke sebuah daerah yang bernama desa Saboung. Desa saboung merupakan desa yang ada di daerah Sambas yang berdekatan dengan daerah Subah. Kalimat itu diulang kembali pada larik pertama dan kedua bait pertama. Perulangan itu berfungsi untuk mempertegas makna kalimat tersebut.

Apelah muattan jeluttoung gattah jeluttoung mengimplikasikan bahwa di dalam kapal belon tersebut memuat getah jeluttoung (karet). Berkemungkinan juga yang dimuatkan dalam kapal pada masa itu bukan hanya karet (Gattah Jeluttong), tetapi juga emas. Kerana pada umumnya Kesultanan Sambas atau Kerajaan Sambas menyimpan banyak sekali sejarah mengenai emas dan tambangnya. Kalimat pada larik pertama yang diiulang kembali pada larik kedua, dan larik ketiga diulang kembali pada larik keempat. Perulangan dilakukan untuk mempertegas makna kalimat 
itu.

Ya baju ya baju merah, baju merah silendang gadoung

Sodah na' sukke mbirrah, tahhan tahhan nafsu digantoung

Sodah na' sukke mbirrah tahhan nafsu di gantoung

Pada larik pertama, baju merah silendang gadong adalah baju yang warnanya merah dan selendangnya berwarna hijau muda. Mengapa bajunya harus warna merah? karena baju warna merah menarik perhatian orang lelaki dan dapat membangkitkan nafsu bagi yang memandangnya. Pada bait kedua mengimplikasikan agar orang-orang Sambas yang sudah kaya jangan suka membirah dan tahan nafsu digantung. Nafsu digantoung maksudnya jangan terlalu mengikuti keinginan atau hawa nafsu. Kalimat itu diulang kembali pada larik kedua dan ketiga bait kedua yang fungsinya untuk mempertegas makna kalimat tersebut.

Sari borneo namenye kapal, masouk sambas silalu sakal

Nakhodenye inda' berakal, taukan batu maseh di baddal

Taukan taukanlah batu maseh di baddal

Pada bait itu mengimplikasikasikan laki-laki yang lupa diri karena mentang-mentang sudah kaya berbuat sesuka hati sehingga dikatakan tidak berakal. Tidak berakal berarti tidak berpikir panjang dan tidak memikirkan akibat yang ditimbulkan dari perbuatannya tersebut. Kata batu dibaddal makna konotatifnya adalah sudah tahu perbuatan itu tidak baik masih dilakukan. Perulangan kembali pada larik ketiga dan keempat bait ketiga fungsinya untuk mempertegas makna kalimat itu.

Sulthan Sambas sullohlah nagri

Ge' mare' jaman uddah bepassan

Jagelah anak binni

Mun da' dijage dimakan jaman

Bait terakhir tersebut merupakan pantun nasihat untuk seorang lelaki yang sudah berkeluarga (ayah). Kata Sulthan Sambas dan bepassan berarti dari dahulu nenek moyang sudah memberikan pesan nasihat kepada generasi yang akan datang. Bait di atas ini mengimplikasikan kepada lelaki yang sibuk mencari uang agar anak istri dijaga dan dibimbing karena dikhawatirkan akan di makan jaman. Dimakan jaman bukan berarti jaman bisa makan anak istri tetapi merupakan kalimat konotasi yang mengandung makna bahwa jika anak dan istri tidak dijaga dan dibimbing maka akan 
mudah tergiur dengan kehidupan dunia yang hanya sementara ini.

\section{Hipogram Aktual}

Untuk menemukan hipogram aktual dapat diamati di dalam teks yang telah ada sebelumnya. Hipogram aktual bersifat nyata atau eksplisit. Dikatakan bersifat nyata karena lirik-lirik lagu yang diciptakan oleh orang zaman dahulu adalah berdasarkan adat istiadat atau budaya dan ceritacerita dari kehidupan yang telah ada sebelumnya.

Hipogram aktual adalah terdapat di dalam teks lirik lagu. Latar penciptaan pada lagu "kapal belon" ini adalah untuk menceritakan kapal yang amat besar yang mengangkut berbagai komoditas ekspor Kesultanan Sambas. Karena pada zaman kesultanan, Sambas adalah satu di antara pusat perdagangan di Nusantara (Kontrak Dagang Tertua di Indonesia adalah antara Kesultanan Sambas dengan VC (1603); arsip nasional). Mungkin saja yang dimuatkan pada kapal-kapal pada saat itu bukanlah hanya karet (Gattah Jeluttong) tetapi juga emas, karena kesultanan Sambas atau Sambas pada umumnya "menyimpan" banyak sekali sejarah mengenai emas dan tambangnya.

\section{Matriks dan Model}

Matriks adalah kata kunci yang puitis dan melahirkan beberapa kalimat. Model merupakan aktualisasi pertama dari matriks. Aktualisasi pertama dari matriks ini berupa kata atau kalimat tertentu yang khas dan puitis. Kekhasan dan kepuitisan model itu mampu membedakan kata atau kalimat-kalimat lain dalam puisi tersebut. Eksistensi kata itu dikatakan puitis bila tanda itu bersifat hipogramatik dan monumental.

Ada dua tanda yang tampaknya monumental dalam lagu "Kapal Belon", yaitu (1) judul lagu itu sendiri "kapal belon", dan (2) kalimat terakhir dalam lagu itu, "jagelah anak binni, mun da' dijage dimakan jaman". Kedua kalimat itu memiliki kekuatan puitis yang hampir sama. Yang pertama menceritakan tentang sejarah kapal belon. Oleh karena itu, kata tersebut digunakan sebagai judul lagu yang memiliki kekuatan puitis yang bersifat hipogramatik dan monumental. Perulangan sebanyak dua kali menunjukkan betapa penting dan puitisnya kalimat tersebut.

Selain hal di atas, model pertama matriks kalimat puitis "kapal belon" menunjukkan sebuah kapal yang amat luar biasa. Pada saat itu Sambas adalah satu di antara pusat perdagangan di Nusantara. Dari judul lagu itu 
kemudian melahirkan kalimat-kalimat puitis yang lain, seperti "ya kapal ya kapal belon, kapal belon nujju ke saboung, "apelah muatan jeluttong, gattah jeluttong".

Model kedua berangkat dari kalimat terakhir bait keempat yang mengungkapkan bahwa anak istri harus dijaga karena kalau tidak dijaga dimakan jaman. Kata dijaga dan dimakan jaman mengandung makna yang mendalam. Dari kalimat tersebut melahirkan kalimat-kalimat puitis yang lain.

\section{SIMPULAN}

1. Lahirnya seorang anak muda bernama Mulam Husairi Walid yang memiliki wawasan yang tinggi untuk mengangkat kembali kehebatan Melayu di persada dunia.

2. Lahirnya Mulam Husairi Walid sebagai pencipta yang dapat mengekspresikan wawasan kemelayuan dari perspektif kesenian.

3. Pemikiran yang dijana dapat melahirkan kembali usaha-usaha ke arah kebangkitan Melayu.

4. Pemikiran dalam lagu 'Kapal Belon' menunjukkan jati diri Melayu supaya kembali ke akar kemelayuan dengan mengamalkan Islam sebagai cara hidup.

5. Lirik-lirik lagu Melayu Sambas dalam album The Teriggas of Sambas pada tahap pembacaan semiotika pertama (heuristik) membuahkan sebuah heterogenitas yang ungramatikal, terkoyak-koyak, dan tidak terpadu. Seolah-olah tidak ada kesinambungan baris demi baris atau bait demi bait dalam puisi tersebut.

6. Pada pembacaan heuristik belum ditemukan pemahaman makna secara total sehingga dilakukan pembacaan hermeneutik. Pembacaan hermeneutik adalah pembacaan semiotika tingkat kedua yang diperoleh sebuah makna yang terpadu. Kalimat kapal belon menjadi model pertama matriks yang menceritakan sebuah kapal yang sangat besar yang mengangkut barang dari Sambas ke luar negara. Dari kata kapal belon menggambarkan kondisi perekonomian yang sangat maju dan berkembang dengan pesat pada saat itu.

7. Diharapkan usaha-usaha yang telah dilakukan akan berterusan dan mendapat sokongan daripada semua pihak. 


\section{BIBLIOGRAFI}

Gallop, Annabel Teh \& Arp. Benard, 1991. Golden Letters: Writing Traditional of Indonesia. London: The British Library/Yayasan Lontar.

Melayu Online. Kesultanan Sambas. http://melayuonline.com/ind/ history/dig/67/kesultanan-sambas. Dilihat pada 15 Juni 2012

Mu'jizah, 2009. Iluminasi dalam Surat-surat Melayu Abad ke-18 dan ke-19, Jakarta:KPG dan Pusat Bahasa.

Pabali H. Musa. 2003. Sejarah Kesultanan Sambas Kalimantan Barat: Kajian naskah asal raja-raja dan salasilah Raja Sambas. Pontianak: STAIN Pontianak Press, Yayasan Adikarya IKAPI, dan The Ford Foundation.

Pradopo, Rachmat Djoko. 2009. Pengkajian puisi.Yogyakarta: Gadjah Mada University Press.

Ratna, Nyoman Khuta. 2009. Penelitian sastra. Yogyakarta: Pustaka pelajar.

Santosa, Puji. 1993. Ancangan Semiotika dan pengkajian Susastra. Bandung: Angkasa

Urai Riza Fahmi. 2003. Selayang Pandang Kerajaan Islam Sambas. Sambas: Mutiara.

Yudithia Ratih. tanpa tahun ."Istana Alwatzikubillah-Sambas", dalam Istana-istana di Kalimantan Barat. Inventarisasi Istana di Kalimantan Barat. 